\title{
Analysis of the performance of a Flying-Capacitor Three Level Buck Converter Topology
}

\author{
${ }^{1}$ Reshmi Elias, ${ }^{2}$ Ms. Sreedevi G. \\ ${ }^{I}$ M.Tech Research Scholar Electrical and Electronics Engineering Govt. Engineering College, Idukki, India \\ ${ }^{2}$ Asst. Professor Electrical and Electronics Engineering Govt. Engineering College, Idukki ,India
}

\begin{abstract}
A comparative study of the flying capacitor three level buck converter and a modified flying capacitor three level converter is done here. And analysis of the modified flying capacitor three level buck converter is done from the waveforms obtained. The main benefits of this topology is reduction in size of the converter and also higher efficiency. The conventional and the proposed circuits are simulated using PSIM.
\end{abstract}

Index Terms: Flying capacitor Buck converter, dynamic response.

\section{Introduction}

As the voltage stress on the switches is smaller by using a flying capacitor buck converter, it is mainly used in applications which requires high power.

Advantages of using this topology are voltage stress on the switches are reduced by half ,size of the inductor is reduced and efficiency is increased as in [2],[3] and as a result of this converter become more compact. And the switching losses are also reduced.

In this paper the simulation of a Flying capacitor three level buck converter and modified flying capacitor three level buck converter is done. The simulation model is done using PSIM.

One of the disadvantages of using this modified flying capacitor three level buck converter is switching loss will be more as there are three switches.

In section II a flying capacitor three level buck converter has been suggested. section III simulation parameters are given. Section IV presents the simulation model of flying capacitor and modified flying capacitor three level buck converter. And section $\mathrm{V}$ provides the simulation results of flying capacitor buck converter and modified flying capacitor buck converter followed by the conclusion about the proposed topology in section VI.

\section{Flying Capacitor Three Level Buck Converter}

Flying capacitor three level buck converter topology has been illustrated in Fig 1.It consists ot two switches S1 andS2, two diodes D1 and D2,inductor,filter capacitor and a resistive load. Using this converter we will be able to get 3 voltage level zero, $\frac{1}{2}$ Vin and Vin.When switches S1 and S2 are conducting, the entire input voltage appears across the output and the voltage Vx will be equal to Vin And second case is switch S1 and diode D2 conducts. So capacitor gets charged and the output voltage is 0.5 Vin .Similar is the case when switch $\mathrm{S} 2$ and diode D1 is conducting. Here capacitor gets discharged and output voltage is found to be $0.5 \mathrm{Vin}$. When both the diodes are conducting the current freewheels and the output voltage equals 0 .

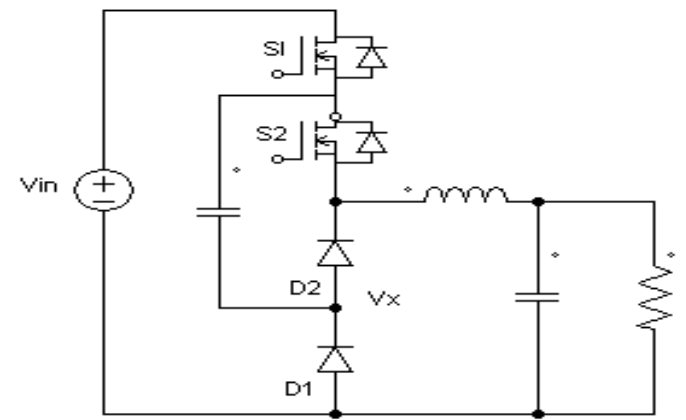

Fig. 1 Flying Capacitor Three level buck converter

In the normal case the possible output voltage levels are 0 and $\mathrm{Vi}$. The third additional voltage level of $0.5 \mathrm{~V}$ reduces the size of the inductor.

It is seen that the two switches are driven 180 degree out of phase with each other and as a result the voltage stress on the switches is halved. Compared to a buck converter for the same current ripple three level buck converter has smaller value of inductance. 
In conventional buck converter possible output voltages are 0 and Vin. Hence the dynamic response is slower and the inductor current ripple is larger.

In order to improve the dynamic response, the inductor can be made smaller and the minimum value of inductance can be obtained using the equation

$\mathrm{L}_{\min }=\left(1-\frac{2 V o}{V i n}\right) \frac{R T}{2}$

Thus the overall size of the conductor can be reduced using a buck converter topology

. And power density will be higher because of lower inductor size. The ripple current frequency is doubled, so that the switches are subjected to low switching frequency than that of conventional buck converter.

Since the switches are subjected to half the input voltage, the voltage across the switches are also reduced.

In this topology the inductor current slew rate during load step up and load step down are given as

$$
\begin{aligned}
& \frac{d I L}{d t}=(0.5 \text { Vin }-V o) / L_{L^{(2)}} \\
& \frac{d I L}{d t}=\left(\frac{(-V o)}{L}\right)
\end{aligned}
$$

And the dynamic response of buck converter depends on the inductor current slew rate also. An additional switch called auxiliary switch $\mathrm{Sa}$ and auxiliary diode $\mathrm{Da}$ are connected This gives the modified circuit which is given in Fig. 2.

When the auxiliary switch Sa is turned off, Da will not conduct. So the operation is similar to that of conventional flying capacitor three level converter. And when Sa conducts S1 and S2 will also be turned on. And when there is a decrease in load all the three switches are turned on

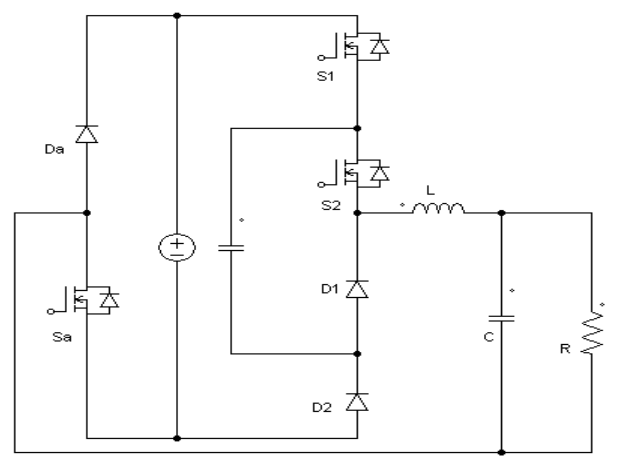

Fig. 2 Modified Flying Capacitor converter topology

\section{Simulation Parameters}

The values of the parameters used for the simulation of the Flying capacitor three level buck converter are input voltage is taken as $24 \mathrm{~V}$.Here the load used is having $120 \Omega$ resiatance. Inductor used here is $300 \mu \mathrm{H}$. And the flying capacitor is having a capacitance of $27 \mu \mathrm{F}$ Here the switching frequency is taken as $5000 \mathrm{~Hz}$. 


\section{Simulation Model}

A. Flying Capacitor Three Level Buck Converter

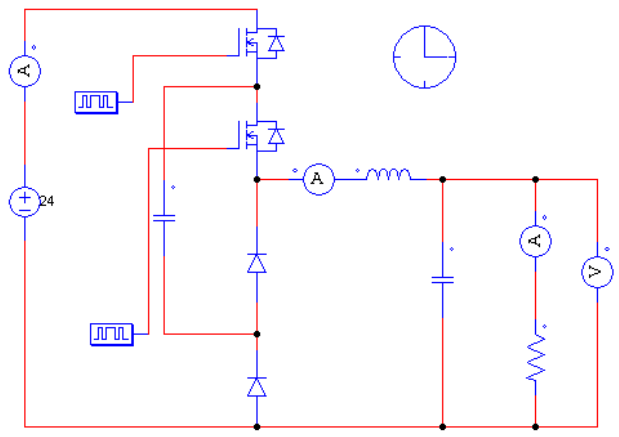

Fig. 3. Circuit layout of Flying Capacitor three level buck converterin PSIM

Fig.3Shows the circuit layout of a flying capacitor three level buck converter in PSIM. In this input voltage is given as $24 \mathrm{~V}$. and the flying capacitor is having $27 \mu \mathrm{F}$.Inductance value is taken as $300 \mu \mathrm{H}$. This circuit shows the conventional flying capacitor three level buck converter.

B. Modified Flying Capacitor Three Level Buck Converter

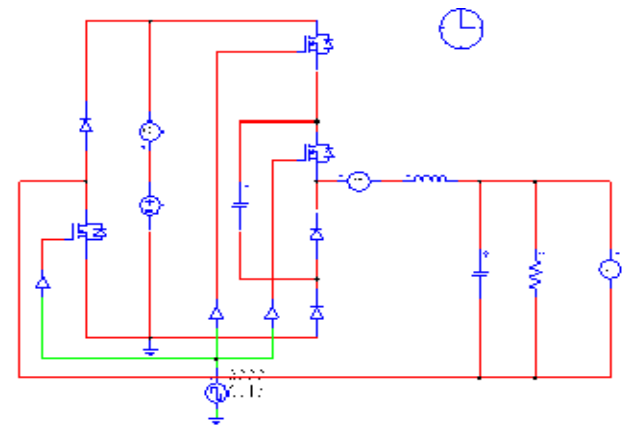

Fig. 4. Circuit layout of Modified Flying Capacitor three level buck converter in PSIM

The simulation parameters are same for both the circuits. The above Fig. 4 gives the simulation model of modified flying capacitor three level buck converter.

\section{Simulation Results}

A. Flying Capacitor Three Level Buck Converter

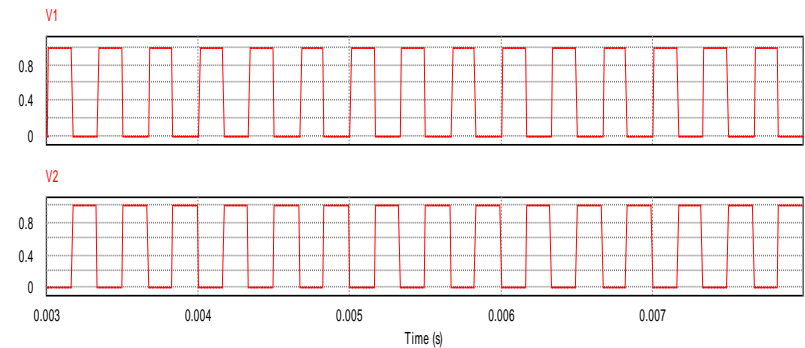

Fig 5. Control signal for switches S1 and S2

The control signals for switching of switches S1 and s2 are given in Fig. 5. And it can be seen that switching signals are applied to only one switch at a time. 


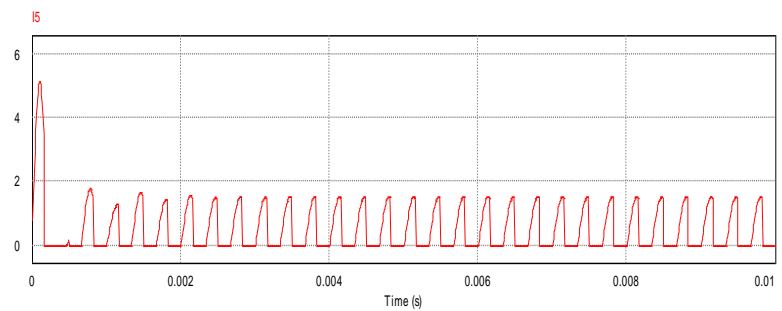

Fig. 6. Input Current

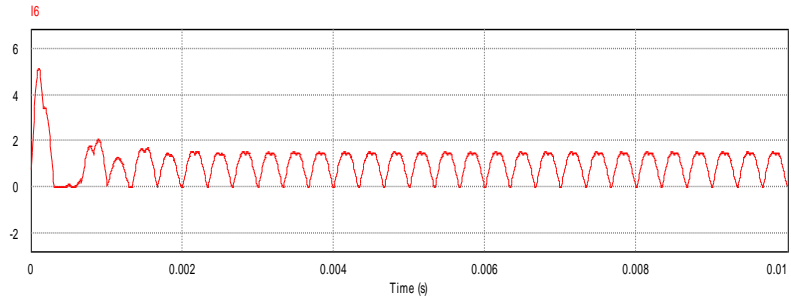

Fig. 7. Inductor current

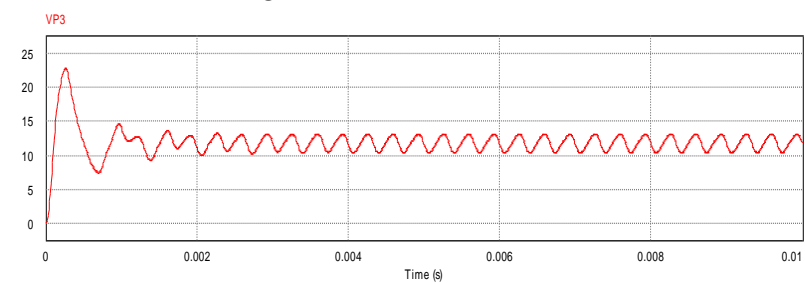

Fig. 8. Output of three level buck converter

B. Modified Flying Capacitor Three Level Buck Converter
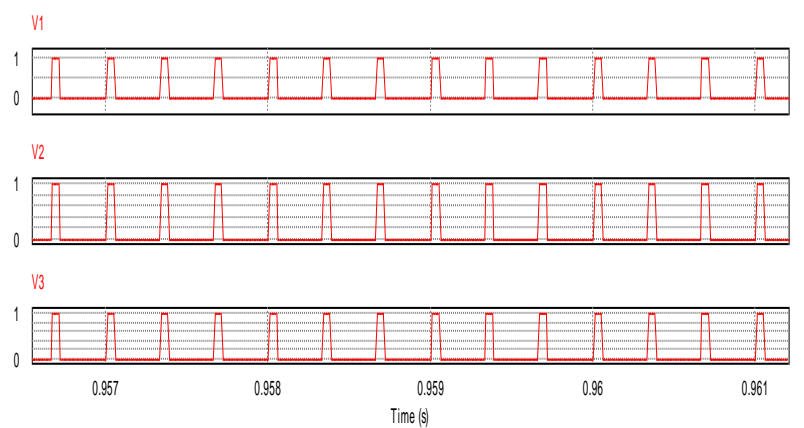

Fig. 9. Control signals for auxiliary switch, switch S1and Switch S2

Fig. 9 shows the control signals for the three swiches. Here all the three switches are switched at the same instant.

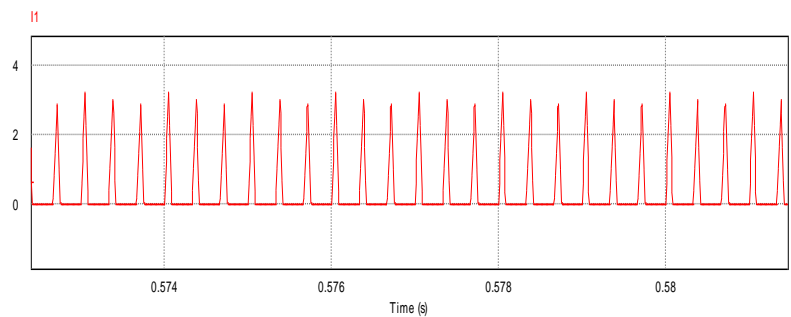

Fig. 10. Input currents. 


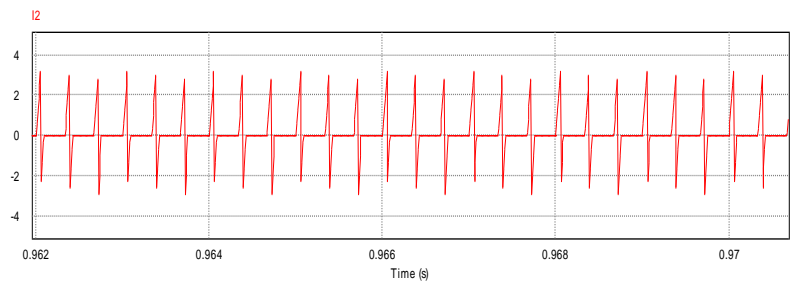

Fig 11. Inductor Current

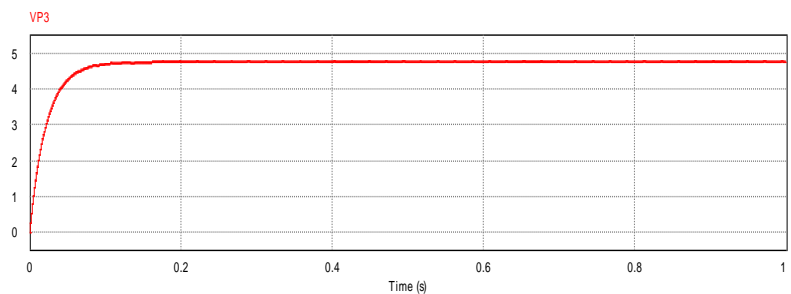

Fig. 12. Output Voltage of modified three level buck converter

By comparing the conventional and modified topology it is clear the output voltage obtained using the conventional topology is $12 \mathrm{~V}$ but by using modified topology it has been reduced to about $6 \mathrm{~V}$. The ripples in output voltages is reduced by using the modified topology.

\section{Conclusion}

A comparative study of flying capacitor three level buck converter and a modified flying capacitor three level buck converter is done. And it has been found that in flying capacitor buck converter the control signals are given to only one switch at a time. But for modified flying capacitor buck converter all the switches are conducting at the same time. By using this topology the converter has become more compact.

But the disadvantage of using modified topology is the switching losses is more .The simulation model is set up using PSIM and the waveforms with improved response are obtained.

\section{References}

[1]. Lisheng Shi, BhanuPrashantBaddipadiga,MehdiFerdowsi,andMariesa L, "Improving the Dynamic Response of a Flying-Capacitor Three-Level Buck Converter," IEEE Trans. Power Electron., vol. 28,no. 5, May. 2013.

[2]. J. Zhao, T. Sato , T. Nabeshima, and T. Nakano, "Steady-state and dynamic analysis of a buck converter using a hysteretic PWM control," in Proc. IEEE 35th Annu. Appl. Power Electron. Spec. Conf., Jun. 2004, vol. 5, pp. 3654-3658.

[3]. V. Yousefzadeh, E. Alarc'on, and D. Maksimovic, "Three-level buck converter for envelope tracking applications," IEEE Trans. Power Electron., vol. 21, no. 2, pp. 549-552, Mar. 2006. 